\title{
Ecological and biological features of the development of introduced species of the genus Abies Mill
}

\author{
Lubov Masalova*, Olga Emelyanova, Mikhail Tsoy, Galina Pavlenkova, and Andrey Firsov
}

Russian Research Institute of Fruit Crop Breeding (VNIISPK), 302530 Orel, Russian Federation

\begin{abstract}
Against the background of man-made impact on the environment, the role of landscape architecture increases. Green plantings reduce the impact of adverse factors. A special role is given to coniferous plants that perform environmental-improving functions all year round. The collection of the VNIISPK arboretum includes more than 310 species, forms and varieties of woody plants representing 31 families. The most numerous family of Pinaceae includes 5 genera, one of which is the genus Abies Mill. The purpose of the study is a comprehensive assessment of ecological and biological features of the genus Abies of different origin to justify the success of the introduction in conditions of the Central Chernozem region of Russia. All the studied species have high winter hardiness in the conditions of the central part of Russia.A. balsamea, A. concolor, A. fraseri, A. lasiocarpa, and A. sibirica were resistant to infectious diseases. A. alba, A. concolor, A. fraseri, A. nephrolepis, A. sachalinensis and A. veitchii showed resistance to pests. According to the results of comprehensive assessment of the ecological and biological features of 9 introduced species of the genus Abies, three highly decorative genotypes of North American origin, resistant to a complex of adverse environmental factors, were identified: A. balsamea, A. concolor, and A. fraseri.
\end{abstract}

\section{Introduction}

The increased anthropogenic impact on the biosphere has led not only to global environmental perturbations and decrease in the level of environment comfort, but also has created conditions that are dangerous for human health [1-5]. Against this background, the role of landscape architecture is increasing as one of the main directions of creating a harmonious human environment. Natural and artificial green plantings, including urban and suburban forests, parks and other green areas of various functional purposes, directly related to both the aesthetic properties of the living environment and the ecological ones, perform primarily environmental functions and are of vital importance for human [2-8]. Plants have a beneficial effect on the microclimate, moisturize and enrich the air with oxygen, reduce noise, serve as a natural filter that absorbs dust, and improve the radiation regime. By adsorbing a significant amount of toxic components, including heavy metals,

\footnotetext{
${ }^{*}$ Corresponding author: masalova@vniispk.ru
} 
from the air and neutralizing them in the tissues, and releasing phytoncides, they contribute to maintaining a healthy gas balance in the atmosphere [2, 4-6, 9-15]. However, when working on the creation of landscaping objects, it should be taken into account that woody plants differ significantly from each other in terms of stability in urban environment. Currently, specialists face two main tasks: the preservation of existing green areas and the creation of new green plantings, which must have great resistance to anthropogenic pressure and meet high aesthetic requirements $[12,16]$.

In central part of Russia, where all native foliaceous plants are deciduous, it is impossible to create a garden or park that performs its sanitary and hygienic functions all year round and retains its attractiveness, without coniferous plants, most of which are evergreen [11]. At the same time, the impact of negative factors of the urbanized environment contributes to the formation of an assortment with a limited species composition of woody plants, which makes it necessary to search for introduced plants to create a sustainable landscaping system $[13,14]$.

Green plantings are leveled by unfavorable factors of natural and man-made origin, are exposed to chemical, physical, biological and complex pollution. The high degree of influence of urbanized territories negative factors often leads to vegetation weakening, damage by diseases and pests, loss of their biological stability, decrease in decorative properties, premature aging and trees drying [5, 8, 13, 17-20].

According to L. N. Kovrigina [11] coniferous species that have low level of metabolism, long-term assimilation organs and imperfect conducting system in comparison with foliaceous ones, and are the most sensitive to urban environment pollution. O.N. Kulikova believes [6] that many species of coniferous plants, when they are transferred to new conditions (i.e., to introduction conditions), are resistant to gas contamination and smoke, are durable, decorative, fast-growing, and superior to local species in biological or technical properties. Despite the long period of study, the choice of forms and varieties introduced and promising for gardening is associated with a lack of data on their stability and prospects $[11,14,21]$.

Botanical gardens and arboretums study the adaptation of woody introduced species to changing environmental conditions [22]. To this date, the collection of the arboretum of the Russian Research Institute of Fruit Crop Breeding (VNIISPK, Russia) includes more than 310 species, forms and varieties of woody plants representing 31 families. Representatives of the coniferous plants class make up $25 \%$ of the total number of taxa and are represented by three families: Pinaceae Lindl, Cupresaceae Neger and Taxaceae Lindl. The most numerous family of Pinaceae in terms of the number of species includes 5 genera [23], one of which is the genus Abies Mill. All species of this genus in our collection are introduced species.

Abies is a genus of evergreen forest-forming gymnosperms. These are pyramidal trees up to 60 meters high, having ringed horizontal branches. The life span is 150-200 years. Representatives of the genus Abies are quite cold-hardy, but are sensitive to drought and industrial air pollution [14, 24, 25].

The VNIISPK rrboretum is located in the European part of Russia, $368 \mathrm{~km}$ to the southwest of Moscow $\left(53^{\circ} 00^{\prime} \mathrm{N}, 36^{\circ} 00^{\prime} \mathrm{E}\right)$, one and a half kilometers from the city of Orel in the immediate vicinity of the busy Orel-Bolkhov highway, from which it is separated by a single-row planting of small-leaved linden. According to the research of L. N. Kovrigina [11] the use of coniferous trees in the protective zones of industrial enterprises and in plantings along highways with heavy traffic is impractical, since this reduces their resistance to other negative environmental factors. The presence of a highway in the experimental conditions allows to identify plants that are resistant to anthropogenic loads. The purpose of the study is a comprehensive assessment of ecological and biological 
features of the genus Abies of different origin to justify the success of the introduction in conditions of the Central Chernozem region of Russia.

\section{Materials and methods}

The objects of the study were plants of 9 species of the genus Abies growing in different geographical zones of the genetic collection of the VNIISPK arboretum (Table 1). The research was conducted from 2012 to 2020 . Annual increments were studied from 2018 to 2020. The following methods were used: determination of winter-hardiness - visually in the field conditions at the end of budding on a 7-point scale of P.I. Lapina and S.V. Sidneva [26], where 1 is the highest score of winter-hardiness; the general condition of plants on a 3-point scale of A. G. Golovach [27], where 1 is the best state; determination of resistance to diseases and pests - by visual inspection with regard to the influence of this factor on the decorativeness, in connection with this proposed 3-point scale $(0$ - no damage (affect), 1 there is damage (affect) without loss of decorativeness, 2 - damage (affect) is present with loss of decorativeness). The height measurements of the studied plants were carried out with a Nikon Forest Pro altimeter.

Statistical processing of the research results was carried out by variance analysis method (ANOVA). The significant difference between the varieties (LSD) was calculated with a 5\% significance level. The calculations were performed using the Microsoft Excel 2016 software package.

Table 1. Research objects

\begin{tabular}{|l|c|c|c|c|}
\hline \multicolumn{1}{|c|}{ Species } & Natural growth area & $\begin{array}{c}\text { Year of } \\
\text { planting in } \\
\text { arboretum }\end{array}$ & $\begin{array}{c}\text { Number } \\
\text { of plants } \\
\text { condition } \\
\text { as of } \\
01.10 .20 \\
20\end{array}$ \\
\hline Abies alba Mill. & Western Europe & 1974 & 10 & 2 \\
\hline Abies balsamea Mill & North America & 1968 & 2 & 1 \\
\hline Abies concolor (Gord.) Engelm. & North America & 1968 & 9 & 1 \\
\hline Abies fraseri (Purch)Poir. & North America & 1977 & 16 & 1 \\
\hline Abies lasiocarpa (Hook.) Nutt. & North America & 1977 & 10 & 2 \\
\hline $\begin{array}{l}\text { Abies nephrolepis } \text { (Trautv. ex Maxim.) } \\
\text { Maxim. }\end{array}$ & Far East & 1968 & 1 & 3 \\
\hline Abies sachalinensis (F.Schmidt) Mast. & Far East & 1968 & 5 & 1 \\
\hline sibirica Ledeb. & Siberia & 1977 & 11 & 2 \\
\hline Abies veitchii Lindl. & Far East & 1977 & 2 & 2 \\
\hline
\end{tabular}

\section{Results and discussion}

The prospects of introduction largely depend on winter-hardiness, that is, on the ability of plants to withstand a complex of environmental influences during the winter and early spring periods. This factor depends on the biological characteristics of woody plants, their age and growing conditions [6, 28,29]. According to the results of our research, all objects of the genus Abies have a high winter-hardiness (1 point) in the conditions of the central part of Russia.

The assessment of the general condition of plants of the genus Abies was carried out by us at the end of the growing season of each year of research. Deterioration of the condition of adult coniferous plants, as a rule, leads to irreversible damage, since dead needles and 
dried branches are not restored. Respectively, the condition of the research objects as of 01.10.2020 reflects the total result for this indicator for the entire period of research (Table 1). It was found that $A$. nephrolepis is in poor condition and has a weak vitality, which is associated with the low resistance of this species to diseases. The plant of this species is noticeably weakened, the growth of shoots is weak, the color of the needles is pale, the cones are not formed. Satisfactory condition (medium vitality) was recorded in A. alba, $A$. lasiocarpa, A. sachalinensis, $A$. sibirica, and A. veitchii. The shoots growth, development and brightness of the needles color in these species did not reach the maximum. Three of the studied objects (A. balsamea, A. concolor, and A. fraseri) had good vitality. These species had a dense symmetrical crown, healthy appearance, good annual growth, and typical shoots and needles throughout the entire observation period. A large number of cones with full-fledged seeds were formed on the plants. The growth of Abies plants in the arboretum at a close distance from the highway did not affect their general condition.

One of the important indicators of plant resistance in the conditions of introduction is their resistance to pests and diseases. During the years of research, we have recorded physiological and infectious diseases of Abies. In individual specimens of A. alba, $A$. concolor, and $A$. fraseri, there was a slight physiological drying of the branches due to the thickening of individual plantings. There were pine-leaf cast, brown pine-leaf cast and needles brown streak amoung infectious diseases. The causative agent of pine-leaf cast is the fungus Lophodermium nervisequium (DC.) Rehm. On some branches of A. nephrolepis, $A$. sachalinensis and $A$. veitchii, the two-year-old needles became brown, with small, oblong, black fruit bodies visible on needle underside. The brown needles fell off by autumn. Fungi Herpotrichia juniperi (Duby) Petr. is the causative agent of brown pine-leaf cast, which was observed on A. alba (fig. 1, A). In the spring, the needles on some branches of individual specimens turned yellow and were covered with a gray-brown web mycelium. In the affected needles, black spherical small fruit bodies of the wintering stage of the pathogen fungus were formed. The needles turned brown and dried up, remaining on the branches. The browning of Abies needles is caused by the fungi Trichosphaeria parasitica Hart. and Rhizosphaera pini (Corda) Maubl. This disease in arboretum conditions was noted on A. nephrolepis. The needles gradually turn brown, but, supported by mycelium threads, they do not fall off immediately. On the underside of the needles, point-shaped spherical fruit bodies are formed. In wet years, individual branches of $A$. nephrolepis are strongly affected ( 2 points), which causes mass needles fall off and branches denudation. All diseases recorded on Abies species reduce the decorative effect of the affected specimens (1-2 points). A. balsamea, A. concolor, A. fraseri, A. lasiocarpa, and A. sibirica were resistant to infectious diseases.

The main pest of Abies during the research period was hermes (Aphrastasia peclinatae Choi.) - a small insect, aphid, black in color, abundantly covered with white pubescence, whose entire life is spent on young shoots. Aphids feed on the underside of the needles, and yellow spots appear on the upper side in these places. During the season, 3-4 generations develop. In large numbers, this type of pest in the arboretum was noted on $A$. lasiocarpa and $A$. sibirica (2 points) (fig. 1, B). Damaged needles turn yellow and fall off, which affects the decorative and general condition of plants of these species. A. alba, A. balsamea, A. concolor, A. fraseri, A. nephrolepis, A. sachalinensis and A. veitchii showed resistance to pests. 

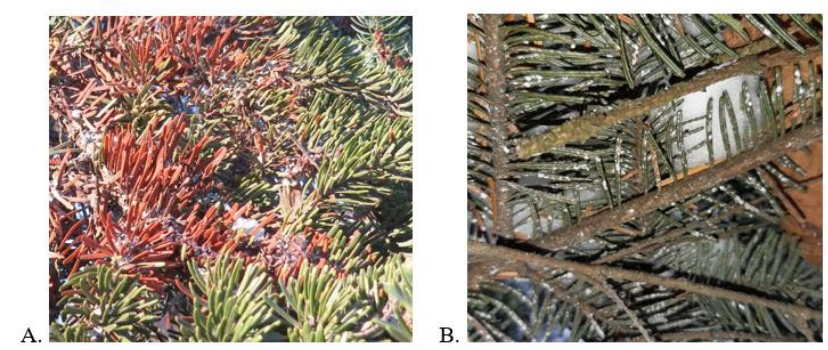

Fig. 1. A - Herpotrichia juniperi on A. alba; B - Aphrastasia peclinatae on A. sibirica

One of the defining properties when selecting an assortment of woody plants for decorative gardening is the size they achieve, growth speed and durability. Measurement of plants height of the genus Abies in arboretum conditions (as of 01.11.2020) showed different variability of this parameter within the species (fig. 2). Slight variation (coefficient of variation does not exceed $10 \%$ ) was observed in 3 species of Abies - A. balsamea, A. sibirica and $A$. veitchii. A. alba has the greatest variability in the value of this indicator (25.5\%). The remaining Abies species studied have an average variation of 10.8 to $18.5 \%$.

Based on the measurements carried out, significant differences in height were revealed between different Abies species. In relation to the majority of the studied species, a significantly low value of this indicator was found in $A$. alba $(13.1 \mathrm{~m})$ and $A$. veitchii $(13.8$ $\mathrm{m})$, while $A$. concolor $(18.5 \mathrm{~m})$ and $A$. sibirica $(17.5 \mathrm{~m})$ had a significantly high value.

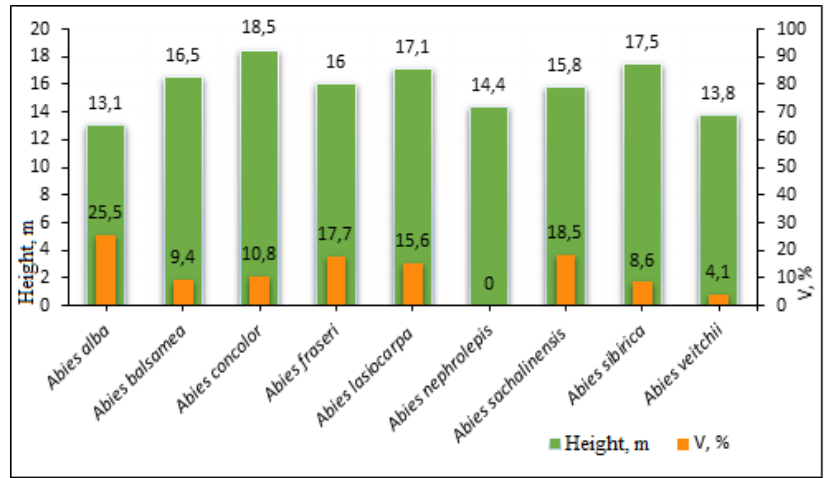

Fig. 2. The average height of plants of Abies species (LSD05 $=1.45)$ and the coefficient of variation of this trait $(\mathrm{V})$.

In nature, A. alba, A. concolor, A. sachalinensis, $A$. sibirica and $A$. veitchii reach quite large sizes (more than $20 \mathrm{~m}$ ) and are trees of the first range. In arboretum conditions, at the moment they are trees of the second range (Table 2), that is, they have not yet reached the typical size for the species. A. balsamea, A. fraseri, A. nephrolepis and A. lasiocarpa rarely reach a height of $20 \mathrm{~m}$ in natural conditions, that is, they are trees of the second range. Studies have shown that in the arboretum, these objects of study have already reached the size typical for the species. Nevertheless, it should be noted that the studied Abies species in the arboretum have an age young enough for representatives of this genus in natural conditions of growth, so they continue their growth and development. Based on this, further observation of these objects of research is of scientific and practical interest from the point of view of studying the dynamics of their growth in connection with longevity. 


\section{Conclusion}

According to the results of comprehensive assessment of the ecological and biological features of nine introduced species of the genus Abies of the genetic collection of VNIISPK arboretum, three highly decorative genotypes of North American origin, resistant to a complex of adverse environmental factors, were identified: A. balsamea, A. concolor, and $A$. fraseri. When these species are introduced into the conditions of the Central Chernozem region of the Russian Federation, a positive result can be predicted.

\section{References}

1. S. Host, E. Chatignoux, C. Leal, I. Grémy, Revue d'Epidemiologie et de Sante Publique, 60(4), 321 (2012)

2. O. Yu. Dubovitskaya, Problems of biological, medical and pharmaceutical chemistry, 11, 20 (2013)

3. J.A. Salmond, M. Tadaki, S. Vardoulakis, K. Arbuthnott, A. Coutts, M. Demuzere, K.N. Dirks, C. Heaviside, S. Lim, H. Macintyre et al, Environmental Health, 15(36), 95 (2016)

4. M.W. Yahia, E. Johansson, S. Thorsson, F. Lindberg, M.I. Rasmussen, International Journal of Biometeorology, 62, 373 (2018)

5. V.P. Bessonova, A.S. Chongova, A.V. Sklyarenko, Biosystems Diversity, 28(2), 203 (2020)

6. O.N. Kulikova, Vestnik IRGSHA, 44(2), 89 (2011)

7. S.J. Livesley, G.M. McPherson, C. Calfapietra, Journal of Environmental Quality, 45(1), 119 (2016)

8. J. Vieira, P. Matos, T. Mexia, P. Silva, N. Lopes, C. Freitas, O. Correia, M. San-tosReis, C. Branquinho, P. Pinho, Environmental Research, 160, 306 (2018)

9. J.G. Pausas, C. Bladé, A. Valdecantos, J.P. Seva, D. Fuentes, J.A. Alloza, A. Vilagrosa, S. Bautista, J. Cortina, R. Vallejo, Plant Ecology, 171(1-2), 209 (2004)

10. C.Y. Jim, W.Y. Chen, Journal of Environmental Economics and Management, 88(4), 665 (2008)

11. L.N. Kovrigina, L.O. Petunkina, Vestnik IRGSHA, 44(1), 73 (2011)

12. L. Salvati, C. Ferrar, A. Mavrakis, A. Colantoni, Journal of Forestry Research, 27(1), 175 (2016)

13. O.Yu. Emelyanova, L.I. Masalova, Contemporary horticulture, 4(24), 113 (2017)

14. M.V. Solovyova, E.S. Zalesova, Actual problems of the forest complex, 51, 217 (2018)

15. Z. Li, D. Chen, S. Cai, S. Che, Plos one, 13(4), 1 (2018)

16. S.L. Rysin, N.A. Trusov, I.O. Yatsenko, Forestry bulletin, 19(5), 140 (2015)

17. G.M. Lovett, T.H. Tear, D.C. Evers, S.E. Findlay, B.J. Cosby, J.K. Dunscomb, C.T. Driscoll, K.C. Weathers, The Year in Ecology and Conservation Biology, 1162, 99 (2009)

18. T.M. Khromova, O.Yu. Emelyanova, M.F. Tsoi, Pomiculture and small fruits culture in Russia, 46, 409 (2016)

19. P.K. Rai, Ecotoxicology and Environmental Safety, 129, 120 (2016)

20. M.B. Nikolić, A.M. Stefanović, M.M Veselinović, D.S Milanović, Applied Ecology and Environmental Research, 17(2), 2831 (2019) 
21. S. Zalesov, A. Opletaev, Pryadilina, R. Damary, The path forward for wood products: a global perspective, 1 (2016)

22. O.Yu. Dubovitskaya, M.F. Tsoi, G.A. Pavlenkova, L.I. Masalova, A.N. Firsov, Horticulture and Viticulture, 3, 46 (2015)

23. O.Yu. Emelyanova, A.N. Firsov, L.I. Masalova, Breeding and cultivation of horticultural crops, 5(2), 29 (2018)

24. V.T. Popova, Actual Directions of Scientific Researches of the XXI Century: Theory and Practice, 5, 379 (2013)

25. V.T. Popova, V.D. Dorofeeva, A.A. Popova, Proceedings of Voronezh State University. Series: Chemistry. Biology. Pharmacy, 1, 125 (2017)

26. P.I. Lapin, S.V. Sidneva, Woody plants of the SBS of the USSR Academy of Sciences, 18 (1975)

27. A.G. Golovach, Trees, shrubs and lianas of the Botanical Garden of the BIN of the USSR Academy of Sciences, 188 (1980)

28. F. Lebourgeois, Cyrille B.K. Rathgeber, E. Ulrich, Journal of Vegetation Science, 21, 364 (2009)

29. Ya.A. Krekova, S.V. Zalesov, N.K. Chebotko, Fruit growing, seed production, introduction of woody plants, 20, 89 (2017) 